\title{
The utility of medico-legal databases for public health research: a systematic review of peer-reviewed publications using the National Coronial Information System
}

\author{
Lyndal Bugeja ${ }^{1,2^{*}}$, Joseph E. Ibrahim, Noha Ferrah', Briony Murphy ${ }^{1}$, Melissa Willoughby ${ }^{1,2}$ and David Ranson ${ }^{3}$
}

\begin{abstract}
Background: Medico-legal death investigations are a recognised data source for public health endeavours and its accessibility has increased following the development of electronic data systems. Despite time and cost savings, the strengths and limitations of this method and impact on research findings remain untested. This study examines this issue using the National Coronial Information System (NCIS).

Methods: PubMed, ProQuest and Informit were searched to identify publications where the NCIS was used as a data source for research published during the period 2000-2014. A descriptive analysis was performed to describe the frequency and characteristics of the publications identified. A content analysis was performed to identify the nature and impact of strengths and limitations of the NCIS as reported by researchers.

Results: Of the 106 publications included, 30 reported strengths and limitations, 37 reported limitations only, seven reported strengths only and 32 reported neither. The impact of the reported strengths of the NCIS was described in 14 publications, whilst 46 publications discussed the impacts of limitations. The NCIS was reported to be a reliable source of quality, detailed information with comprehensive coverage of deaths of interest, making it a powerful injury surveillance tool. Despite these strengths, researchers reported that open cases and missing information created the potential for selection and reporting biases and may preclude the identification and control of confounders.
\end{abstract}

Conclusions: To ensure research results are valid and inform health policy, it is essential to consider and seek to overcome the limitations of data sources that may have an impact on results.

Keywords: Coroners and medical examiners, Injury prevention, Mortality surveillance, National Coronial Information System Public health research

\section{Background}

Historically, the primary role of death investigation agencies was to inform the criminal justice system to establish whether the actions or inactions of another person had contributed to the death [1]. While there was early recognition that the outcomes of the death

\footnotetext{
* Correspondence: lyndal.bugeja@monash.edu

${ }^{1}$ Health Law \& Ageing Research Unit, Department of Forensic Medicine, School of Public Health and Preventive Medicine, Monash University, 65 Kavanagh Street, Southbank 3006, Australia

${ }^{2}$ Coroners Court of Victoria, 65 Kavanagh Street, Southbank, Victoria 3006, Australia

Full list of author information is available at the end of the article
}

investigation process could also play a role in public health and safety [2], this has only been formally realised in a few jurisdictions across the world [3, 4]. To contribute to an evidence-base for public health and safety endeavours, electronic systems have been developed to store material and information generated for coroners and medical examiner's medico-legal investigations of unexpected and unnatural deaths.

Such information comprises socio-demographic characteristics, medical history, circumstances immediately proximate to the death, the results of any forensic medical and scientific tests and the outcomes of legal proceedings. 
The richness of this population-based data makes medicolegal death investigation material a valuable data source for preventive medicine [5].

Increasingly, these data assume a wider use, enabling researchers to examine the nature, distribution and determinants of preventable deaths, and the effects of interventions [5-17]. This is of particular importance to policymakers and practitioners who have a responsibility for population-level health and safety $[1,12,18]$. These advances overcome some of the limitations of the timeconsuming and costly traditional process of mortality data collection for public health research $[10,19]$. It is more detailed and accurate than death certificates or police reports, and circumvents the need for extensive manual searches followed by review of all hard copy documents to identify cases and extract the information of interest [13, 20, 21].

Despite this, concerns remain about potential shortcomings of this dataset format, and the impact on research findings [22]. While electronic access reduces costs, and the time needed for case identification and data collection, discussion of the methodological limitations and strengths of this data for public health research remains rudimentary. The published research literature abounds with studies using different data sources and arriving at opposing conclusions [23]. Therefore, a failure to appreciate the presence and impact of limitations and strengths of data from medico-legal death investigations on research findings may lead to sub-optimal public health policy and intervention programs. In some cases, this may have significant clinical implications as illustrated by the shift in paradigm regarding hormone replacement therapy and risk of cardiovascular disease [24].

We explore this topic by examining the strengths and limitations reported in the published peer-reviewed literature by researchers who used medico-legal death investigation data in their study. We focussed on studies using the National Coronial Information System (NCIS), a national dataset for Australian and New Zealand coronial cases [25]. To date, evaluations of the NCIS focused on its utility as a tool for injury surveillance, and its completeness with ICD-10 coded data [26-29].

The aim of this narrative review was to identify and describe the strengths and limitations of a specific electronic data source for public health research as reported in peer reviewed original research publications, using the NCIS.

\section{Methods}

\section{Definitions}

The NCIS is an Internet-based data storage and retrieval system of all deaths reported to Coroners in Australia and New Zealand since 2000 and 2007, respectively [30]. It comprises coded and free-text data and up to four full text documents generated for the coroners' investigation, namely the summary of text from the police report of death to the coroner, autopsy report, forensic toxicology report, and coroners' findings.

\section{Search strategy}

A systematic search, modelled on the Preferred Reporting Items for Systematic Reviews and Meta-Analyses (PRISMA) Statement [31], comprised a combination of electronic database searches, bibliographical reviews and literature referred by relevant experts. Electronic databases were searched for journal articles from the disciplines of medicine, law, public health, road safety and psychology for the period 1 July, 2000, to 31 July, 2014, restricted to the English language. The databases searched were PubMed, ProQuest and Informit using the search terms NCIS and National Coroners Information System (including the variations Coroner's, Coroners' and Coronial). A general Internet search using the search engines Google and Google Scholar was also conducted to identify additional relevant publications. A list of publications was also provided by the NCIS.

\section{Article identification}

The electronic database search strategy was intentionally broad to maximise the identification of relevant literature as the topic area crosses a number of disciplines. Results from search strategies were exported to EndNote for review and duplicates were removed. The reference lists of publications selected for the review were assessed against the inclusion criteria.

\section{Inclusion criteria}

Publications were included in the review where the NCIS was a primary data source, was original research and was published in a peer-reviewed journal.

\section{Data collection}

Methods to evaluate databases include self-reporting of limitations and strengths, or assessment by peers or external entities (e.g. Cochrane) based on a set of predetermined criteria [32]. We chose the former approach on the premise that strengths and limitations would be identified via the peer-review process [33]. Three authors (author 1, author 4 and author 5) independently reviewed the full text of each publication that met the inclusion criteria and extracted the following information in a Microsoft Excel spreadsheet: author(s); date published; title; death or injury type; publication type; publication name; peer review status; and reported strengths and limitations of the NCIS as a data source (free text). Any disagreement in the classification of a variable was resolved by discussion with a fourth researcher (author 2). If insufficient information was available, the variable was classified as unknown. 


\section{Data analysis}

A descriptive statistical analysis was conducted to describe frequencies of published original research, subject of research conducted, and studies that included a discussion of the strengths and limitations of the NCIS as a data source and the impact on their findings. Authors 1, 4 and 3 independently conducted a content analysis of this information to identify the nature, impact of strengths and limitations of the NCIS as reported by researchers.

\section{Results}

\section{Study selection}

The literature searches and cross-referencing with the NCIS list of publications yielded 147 studies, of which 106 were included (Fig. 1; see descriptive table of studies in Additional file 1).

\section{Study description Journals}

The majority of studies were published in Australia (41/ 106, 38.7\%) and the United Kingdom (34/106, 32.1\%), most commonly in the fields of occupational health and safety $(28 / 106,26.4 \%)$ and medicine (26/106, 24.5\%) (Table 1). Most journals ranked in the first or second quartile $(64 / 106,60.3 \%)$ within their category, although approximately $20 \%(20 / 106)$ of journals were not indexed (Table 1).

\section{Study design}

As expected, in nearly all studies (94/106, 88.7\%), the research design comprised a retrospective case series of deaths (Table 1). Almost half (50/106, 47.2\%) of studies examined data at a national level, and $46(43.4 \%)$ in a single jurisdiction. The annual frequency of publications steadily increased from one in 2003 [34] to 18 in 2013. Where known $(n=104)$, the number of years of NCIS data examined ranged from 1 to 13 years (median $=7$ years; IQR, 6-9; Table 1).

\section{Types of death}

The majority of studies examined unintentional deaths $(42 / 106,39.7 \%)$ and, interestingly, only two investigated assaults and natural deaths (Table 1). Within specific death types, studies most commonly investigated intentional selfharm (27/106, 25.5\%) and deaths resulting from a transport collision (18/106, 17.0\%; Table 1).

\section{Reporting of the strengths and limitations of the NCIS} Thirty (28.3\%) studies reported strengths and limitations, 37 (34.9\%) limitations only and seven (6.6\%) strengths only. Fourteen (13.2\%) studies discussed the impacts of the strengths of the NCIS, whilst 46 (43.4\%) discussed the impacts of limitations.

\section{Strengths}

The reported strengths of the NCIS were classified in five domains (Table 2).

Comprehensive coverage $(\boldsymbol{n}=16 ; 43 \%)$ The most frequently reported strength of NCIS was comprehensive coverage. Studies reported that all or the majority of relevant cases were stored in the NCIS, across variables including indigenous origin, objects or substances producing injury and mechanism of injury. The NCIS was described as the only data source that stores information on all work-related deaths irrespective of employment status and setting [35].

High level of detail ( $\boldsymbol{n}=\mathbf{1 3}$; $35 \%)$ The NCIS was reported to hold more detailed information compared with other mortality datasets such as the Australian Bureau of Statistics [36], particularly regarding causes and circumstances of death [37]. Studies reported that this was in part due to the accessibility of full text documents [38].

Reliability ( $\boldsymbol{n}=\mathbf{1 1} ; \mathbf{2 9 \%})$ Reliability was described as a strength of the NCIS and demonstrated by its consistency with other data sources, such as workers compensation claims [39] and official national statistics [36]. Additionally, studies noted that rigorous coding systems and internal quality assessment operated by the NCIS [40] ensured that the information stored reliably matched that of deaths reportable to coroners [41].

Utility ( $\boldsymbol{n}=\mathbf{9} ; \mathbf{2 4 \%})$ The NCIS was described as a useful tool for death investigation and research on public health and safety. Notably, access to coroners' recommendations was reported to be particularly useful [42].

High data quality $(\boldsymbol{n}=\mathbf{6} ; \mathbf{1 6 \%})$ The NCIS was reported as containing high quality data, albeit with little substantiation provided.

Timeliness $(\boldsymbol{n}=\mathbf{4} ; \mathbf{1 0} \%)$ Timeliness of data was the least often mentioned strength [43].

\section{Impacts of strengths}

Reported impacts included the ability to identify and monitor trends in specific death types [27, 39, 44, 45]. Moreover, NCIS may be of valuable use to both researchers [46] and injury prevention practitioners/policymakers [38], to identify hazards [29, 47], inform the development of prevention strategies [27, 36, 39, 48], and assess their effectiveness [49]. In addition, detailed data enabled the in-depth investigation of specific mechanisms of death, such as drowning [38, 50], or activities such as work relatedness [51]. Finally, the reliability and 


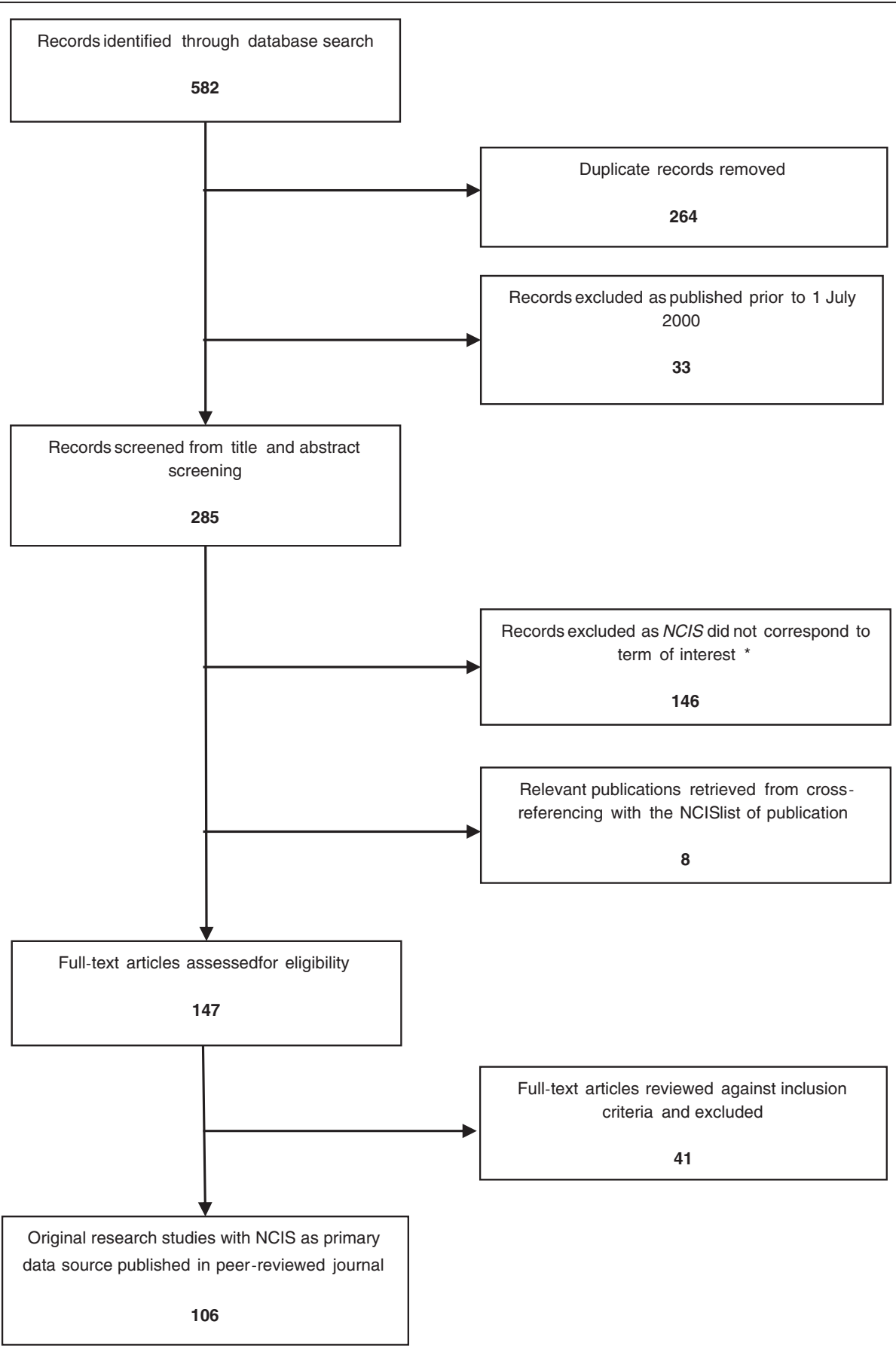

Fig. 1 PRISMA Flow diagram of identification, screening, and inclusion of eligible articles. * The search term NCIS is also an acronym for other organisations and scientific terminology

quality of the data enabled the accurate estimation of mortality $[48,52]$.

\section{Limitations}

Reported limitations of the NCIS were classified in three main domains (Table 3).
Lack of availability $(n=51 ; 76 \%)$ Unavailability of data of interest was the most frequently reported limitation, most commonly within deaths still under investigation (open cases). For records that were available, studies reported that some or all of the full text documents were not attached, and that this varied between jurisdictions $[38,53]$. Lack of availability was also mentioned in relation 
Table 1 Description of journals and publications reviewed $(n=106)$

\begin{tabular}{lll}
\hline $\begin{array}{l}\text { Number of } \\
\text { publications }\end{array}$ & $\begin{array}{l}\text { Proportion of } \\
\text { publications }\end{array}$ \\
$n$ & $\%$ \\
\hline
\end{tabular}

Journal country
Australia
United Kingdom
United States of America/Canada
Germany
Ireland
Switzerland
Netherlands
United Arab Emirates
Journal category

Occupational Health and Safety

Medicine

41

34

14

6 5

Law and Legal Medicine

Psychiatry

Health policy \& services

Pharmacology

Engineering

Other $^{\mathrm{a}}$

$\begin{array}{ll}\text { Q1 } & 33 \\ \text { Q2 } 3 & 31 \\ \text { Q4 } & 12\end{array}$

Not indexed

Design

Retrospective case series

Retrospective cohort

Ecological

Prospective case series

Number of years of data

$$
<2 \text { years }
$$

6-9 years

$\geq 10$ years

Unknown

Intent

Unintentional

All intent

Intentional self-harm

Assault

Natural
Journal ranking quartile within category

2-5 years
38.7

32.1

13.2

5.7

4.7

2.8

1.9

0.9

26.4

24.5

12.3

11.3

8.5

6.6

6.6

3.8

31.1

29.2

11.3

9.4

19.0

88.7

5.7

4.7

0.9

4.7

17.0

58.5

17.9

1.9

39.7

33.0

25.5

0.9

0.9
Table 1 Description of journals and publications reviewed $(n=106)$ (Continued)

\begin{tabular}{|c|c|c|}
\hline \multicolumn{3}{|l|}{ Death type } \\
\hline Intentional self-harm & 27 & 25.5 \\
\hline Transport & 18 & 17.0 \\
\hline Other reportable deaths ${ }^{b}$ & 13 & 12.3 \\
\hline Toxicology & 12 & 11.3 \\
\hline Work & 10 & 9.4 \\
\hline Special groups ${ }^{c}$ & 8 & 7.5 \\
\hline Drowning & 7 & 6.6 \\
\hline Recreation & 7 & 6.6 \\
\hline Location $^{d}$ & 4 & 3.8 \\
\hline \multicolumn{3}{|c|}{$\begin{array}{l}\text { Includes multidisciplinary sciences, sport sciences and social sciences } \\
\text { bIncludes natural deaths, assaults, traumatic brain injuries and other } \\
\text { unintentional deaths } \\
\text { Includes children, Indigenous and Torres Straight Islanders, and prisoners } \\
\text { dIncludes farms, emergency departments and residential aged care }\end{array}$} \\
\hline
\end{tabular}

Completeness $(n=16 ; 24 \%)$ Studies reported that details on historical and proximate circumstances of death were missing from available documents $[50,57,58]$. This precluded a detailed analysis to identify contributing factors to injury (Table 3). Completeness again differed between jurisdictions [38], and while some reports provided detailed descriptions, others contained only minimal information. It was therefore not possible to ascertain from the data stored in the NCIS whether the absence of information meant that it was truly not present or simply omitted [59]. Finally, it was noted that missing information was most prominent between 2000 and 2006 [60].

Accuracy $(n=20 ; 28 \%)$ Studies reported that information in the NCIS may be inaccurate due to coding errors [61-63]. Whilst it was noted that the NCIS conducts a data quality program to review and correct information, this cannot be applied to all records [64]. Additionally, discrepancies between the NCIS and ICD-10 classification system reportedly resulted in a different number of retrieved cases depending on the code-set used [27, 29].

\section{Impacts of limitations}

Impacts of limitations consisted primarily of underreporting of relevant cases, incomplete datasets, misclassification, and the inability to detect trends (Table 3). Studies reported implementing a number of measures to mitigate these shortcomings, including exclusion of open cases or those with missing information, seeking 
Table 2 Strength domains and reported impacts

\begin{tabular}{|c|c|c|c|}
\hline Domain - Information was & $\begin{array}{l}\text { Number of } \\
\text { publications } \\
\text { (proportions) }^{a}\end{array}$ & Justifications & Reported impacts \\
\hline \multicolumn{4}{|l|}{ COMPREHENSIVE } \\
\hline Comprehensive coverage & $16(43 \%)$ & $\begin{array}{l}\text { Captures all reportable deaths across Australia } \\
\text { and New Zealand } \\
\text { Wide breadth of information in closed cases }\end{array}$ & $\begin{array}{l}\text { Monitor mortality trends at population-level } \\
\text { Inform injury prevention programs and } \\
\text { priorities } \\
\text { Assess effectiveness of interventions }\end{array}$ \\
\hline \multicolumn{4}{|l|}{ DETAILED } \\
\hline Detailed data source & $13(35 \%)$ & $\begin{array}{l}\text { Richness of information in closed cases } \\
\text { Greater level of detail than existing databases } \\
\text { (e.g. Australian Bureau of Statistics) }\end{array}$ & $\begin{array}{l}\text { Detailed examination of causes and } \\
\text { circumstances of death }\end{array}$ \\
\hline \multicolumn{4}{|l|}{ RELIABLE } \\
\hline Data consistency & $11(29 \%)$ & $\begin{array}{l}\text { Quality assessment by trained staff at the National } \\
\text { Coronial Information System (NCIS) and internal } \\
\text { quality control } \\
\text { Consistent with other datasets and national } \\
\text { statistics } \\
\text { More reliable than national statistics wherein } \\
\text { data are finalised before coroner's investigation } \\
\text { is closed }\end{array}$ & Accurate estimate of mortality \\
\hline Rigorous coding framework & & Rigorous and consistent coding scheme & \\
\hline \multicolumn{4}{|l|}{ APPLICABLE } \\
\hline $\begin{array}{l}\text { Utility for death investigation } \\
\text { Utility for public health and safety } \\
\text { and injury prevention }\end{array}$ & $9(24 \%)$ & $\begin{array}{l}\text { Hazard identification tool } \\
\text { Coroner's inquest yields constructive } \\
\text { recommendations }\end{array}$ & $\begin{array}{l}\text { Potential for reduction in preventable deaths } \\
\text { Valuable surveillance tool }\end{array}$ \\
\hline \multicolumn{4}{|l|}{ OF HIGH QUALITY } \\
\hline Good quality data & $6(16 \%)$ & $\begin{array}{l}\text { Valid information } \\
\text { Quality assessment by trained staff at NCIS } \\
\text { and internal quality control }\end{array}$ & Contribute to validity of study findings \\
\hline \multicolumn{4}{|l|}{ CURRENT } \\
\hline Most current data source available & $4(10 \%)$ & $\begin{array}{l}\text { Contemporary information } \\
\text { Timely access }\end{array}$ & Not specified \\
\hline
\end{tabular}

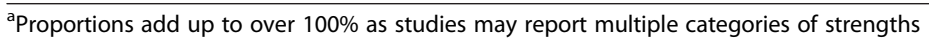

access to paper-based records or other source of information, or adjusting the analysis (Table 3). The exclusion of open cases was achieved in two ways: for all open cases within each year of the study, or for all cases in the last two years of a given study period owing to the delay in case closure [48, 65-68]. Studies acknowledged that this may result in erroneously decreasing trends in mortality where the overall number of cases is small [49, 69], and in selection bias [9] or reporting bias [70] as investigations of deaths that occurred in unequivocal circumstances may be more rapidly completed. As a result, a review of preliminary information was conducted in several studies to identify variables that may be associated with a systematic bias [71]. In addition, analyses both including and excluding open cases reached equivalent results [36], suggesting that excluding open cases does not introduce bias [65]. Furthermore, it was suggested that the effect, if any, was likely to be small due to the overall small number of cases excluded [9]. However, estimation of under-reported cases ranged from
$8 \%$ to $25 \%[49,57,72]$, which may also reduce the sample size and statistical power.

Consequences of missing information on the deceased and circumstances surrounding death rather than on direct causes of death were two-fold. Firstly, case identification was undermined, leading to under-reporting and the inability to monitor mortality trends [37]. A study reported that the NCIS only identified a small subset of reportable deaths amongst ex-prisoners [45]. Secondly, detailed analysis of mechanisms of injury and identification of contributing factors were not always possible. Accordingly, access to paper records was sought [57] and text findings reviewed [56]. Another measure entailed adjusting analysis. In one study, all cases of child fatalities with unspecified family structure were assigned as from an intact biological family [70]; others excluded incomplete cases [60]. Finally, some studies reported the dataset to be too small to monitor trends as it stores cases from 2000, when the NCIS started operating $[47,73]$. 
Table 3 Limitation domains, remediation and reported impacts

\begin{tabular}{|c|c|c|c|}
\hline Domain - Information was not ... & $\begin{array}{l}\text { Number of } \\
\text { publications } \\
\text { (proportions) }^{\text {a }}\end{array}$ & Reported impact on findings & Actions taken \\
\hline \multicolumn{4}{|l|}{ AVAILABLE } \\
\hline \multirow[t]{2}{*}{ Open cases } & \multirow[t]{2}{*}{$23(34 \%)$} & $\begin{array}{l}\text { Under-reporting of potentially } \\
\text { relevant cases }\end{array}$ & $\begin{array}{l}\text { Exclusion of all open cases } \\
\text { Exclusion of recent deaths }\end{array}$ \\
\hline & & Inability to verify information & Used additional data source \\
\hline \multirow[t]{2}{*}{$\begin{array}{l}\text { Whole documents/information of } \\
\text { interest }\end{array}$} & \multirow[t]{2}{*}{$26(39 \%)$} & Unable to conduct detailed analysis & $\begin{array}{l}\text { Access paper-based record } \\
\text { Adjust analysis } \\
\text { Cases not categorised }\end{array}$ \\
\hline & & $\begin{array}{l}\text { Under-reporting of potentially } \\
\text { relevant cases }\end{array}$ & Exclusion of cases \\
\hline Small dataset & $2(3 \%)$ & $\begin{array}{l}\text { Unable to detect trends and evaluate } \\
\text { impacts of interventions }\end{array}$ & Acknowledged limitation \\
\hline \multicolumn{4}{|l|}{ COMPLETE } \\
\hline $\begin{array}{l}\text { Missing data on available info of } \\
\text { interest }\end{array}$ & $16(24 \%)$ & $\begin{array}{l}\text { Missing/incomplete data for analysis } \\
\text { Limitation of level of analysis }\end{array}$ & $\begin{array}{l}\text { Access paper-based record } \\
\text { Cases not categorised } \\
\text { Variables excluded from analyses } \\
\text { Used additional data source } \\
\text { Acknowledged uncertainty (absence of data } \\
\text { does not mean factor not associated) }\end{array}$ \\
\hline \multicolumn{4}{|l|}{ ACCURATE } \\
\hline Potential for human error & $5(7 \%)$ & $\begin{array}{l}\text { Errors in information recording during } \\
\text { inquest (e.g. spelling of drug names) }\end{array}$ & Not specified \\
\hline Potential for human error in coding & $7(10 \%)$ & $\begin{array}{l}\text { Missing data for some variables } \\
\text { Misclassification of variables } \\
\text { Affects accuracy of NCIS }\end{array}$ & $\begin{array}{l}\text { Access paper-based record } \\
\text { Used additional data source } \\
\text { Careful interpretation of reports }\end{array}$ \\
\hline $\begin{array}{l}\text { Misclassification of intent re: intentional } \\
\text { self-harm }\end{array}$ & $5(7 \%)$ & $\begin{array}{l}\text { Under-reporting of potentially relevant } \\
\text { cases }\end{array}$ & Used additional data source \\
\hline $\begin{array}{l}\text { Discrepancies between the National } \\
\text { Coronial Information System (NCIS) and } \\
\text { ICD-10 }\end{array}$ & $3(4 \%)$ & $\begin{array}{l}\text { Under-reporting of potentially relevant } \\
\text { cases }\end{array}$ & Used additional data source (ICD-10) \\
\hline
\end{tabular}

aproportions add up to over $100 \%$ as studies may report multiple categories of limitations

\section{Discussion}

\section{Summary of results}

To illustrate the benefits and hazards of using medicolegal databases in health policy research, this study described the strengths and limitations of the NCIS, as identified in published peer-reviewed studies that used this dataset. The NCIS was reported to be a reliable source of high quality, detailed information with comprehensive coverage of deaths of interest, making it a powerful surveillance and hazard identification tool that enables the examination of spatiotemporal trends, while providing sufficient detail to examine specific processes and outcomes in-depth. The NCIS also averts the previously laborious, slow and costly process of accessing mortality data.

Despite these strengths, studies reported that open cases and missing information created the potential for selection and reporting biases and may preclude the identification of confounders [32]. Our findings are consistent with previous studies examining coronial $[74,75]$ and other health databases $[76,77]$.

\section{Strengths and limitations}

To our knowledge, this is the first study to ascertain the strengths and limitations of the NCIS as determined by the researchers and their scientific peers. Overall, studies were published in a broad range of journals in terms of country of origin, field and level of expertise, which contributes to the generalizability of the results. In addition, a broad and systematic research strategy was employed to identify eligible studies, and a search within the NCIS' own database ensured published studies were not missed. Studies published in peer-reviewed journals were included on the premise that their findings had been subject to the imperfect yet indispensable peer-review process, thus conferring them legitimacy $[78,79]$.

This study has a number of limitations. Restriction to peer-reviewed publications led to the exclusion of a number of studies utilising NCIS and published in the grey literature. Additionally, peer-reviewed journals have a number of shortcomings. The exponential increase in manuscripts submitted for publication, coupled with the lack of qualified referees, may result in the publication 
of studies of substandard quality [80]. Peer-reviewed journals are also susceptible to selective publication bias, whereby studies that fail to demonstrate a significant difference or do not confirm previous results are not published [81]. Reviewers may preclude the appearance and dissemination of findings if these do not fit their own beliefs [82].

Finally, only self-reported biases in selected studies were discussed. Other biases may be associated with the NCIS, yet were not reported. In addition, and consistent with previous studies [83], the majority of studies did not discuss the impacts of limitations on their findings. Authors may have a vested interest in minimising limitations in order to optimise their chance of publication [23].

\section{Implications}

Prior to the emergence of medico-legal databases, the study of unexpected and unnatural deaths primarily consisted of traditional surveillance programs led by government agencies with a public health or safety focus that usually examined specific death types such as deaths in custody. However, their conclusions were limited by incomplete data obtained based on voluntary reporting from local agencies, or by crude information from national statistics such as the National Vital Statistics System in the United States or the Australian Bureau of Statistics in Australia [84].

Population-based health information systems, such as cancer registries, have been used for decades [85] and are becoming increasingly common $[76,77]$. To ensure the outcomes of studies that draw on information from medico-legal databases are valuable and reliably translated, policymakers ought to be aware of their strengths and limitations such as the potential underestimation of suicides. Importantly, datasets such as the NCIS were not designed with the sole purpose of academic research or with specific research questions in mind [76]. As a result, variability in the content and detail of information they contain is a function of the variability within and between coroners and coronial jurisdictions.

A number of recommendations to manage the pitfalls of medico-legal databases emerged from our findings. Researchers should estimate the number of open cases, consider how their exclusion may introduce bias, and take measures to overcome the impact of bias. Additional data sources may optimise accurate case identification and validate information of interest. Consideration should also be given to linkage with other datasets, such as healthcare or employment records [86].

Finally, our findings highlight that overall users of datasets include scant information regarding the biases inherent to their data source. Therefore, another approach to evaluating the quality of medico-legal datasets may be using a systematic criteria-based or program evaluation.
This includes assessing whether the whole dataset or certain elements are consistent with another source, whether expected data elements are present, and whether summary statistics derived from the database fit the expected distribution for a given clinical concept [87].

\section{Future directions}

Our findings can be generalised to other medico-legal databases in countries with comparable public health systems, be applied by researchers to determine whether a given database is a suitable data source to address a particular question, and may inform the design of their study.

The NCIS is the first national database of medico-legal information worldwide. Similar databases exist in the United States (National Violent Death Reporting System) and Canada (Canadian Coroners and Medical Examiner Database). However, they do not capture all unexpected and unnatural deaths nationwide. National databases are cost-effective [88], reduce the bureaucracy associated with conducting research and surveillance initiatives, and may avoid setbacks such as the failure to establish a surveillance program for Creutzfeldt-Jacob disease based on medico-legal data in the United Kingdom due to concerns regarding the independence of Coroners [6]. The development of national medico-legal databases is bound to grow, and our findings will inform their design. The quality of any dataset could be improved; however, this usually involves investment of resources creating a tension between the cost of data and the quality.

\section{Conclusions}

The choice of data source may significantly impact results of studies, and leads to sometimes contradictory conclusions. Using the case of the NCIS, this study identifies the key strengths and limitations of a national medico-legal database as used by public health researchers and vetted by their peers. This information allows researchers, policymakers and practitioners to be better prepared when considering whether a research question is addressed by a given data source and the validity of the study outcome. Hopefully, this will reduce waste of precious resources and result in better public health initiatives.

\section{Additional file}

Additional file 1: Descriptive table of original research studies with NCIS as primary data source published in peer-reviewed journal. (PDF $274 \mathrm{~kb}$ )

\section{Competing interests}

The authors have no competing interests that may constitute a source of bias. Two authors, Dr Bugeja and Prof Ibrahim, are co-authors on 12 publications included in the review. They were not involved in assessing 
these papers, and were instead assessed by two independent reviewers Ms Murphy and Ms Ferrah.

\section{Authors' contributions}

LB is the first author and contributed to the conception and development of the ideas, drafting and critical revision of the article draft, and final approval. JEl contributed to the conception and development of the ideas, drafting and critical revision of the article draft, and final approval. NF contributed to the assessment of studies, drafting and critical revision of the article draft, and final approval. BJM and MW conducted the search and assessment of studies. DLR contributed to critical revision of the article draft and final approval.

\section{Acknowledgements}

The authors thank Ms Natalie Johnson (NCIS Manager) and Ms Jessica Jackson (NCIS Deputy Manager) for their assistance with the identification of eligible publications and for reviewing the manuscript. This research received no specific grant from any funding agency in the public, commercial or not-for-profit sectors.

\section{Author details}

${ }^{1}$ Health Law \& Ageing Research Unit, Department of Forensic Medicine, School of Public Health and Preventive Medicine, Monash University, 65 Kavanagh Street, Southbank 3006, Australia. ${ }^{2}$ Coroners Court of Victoria, 65 Kavanagh Street, Southbank, Victoria 3006, Australia. ${ }^{3}$ Victorian Institute of Forensic Medicine, 65 Kavanagh Street, Southbank 3006, Australia.

\section{Received: 29 September 2015 Accepted: 24 March 2016 Published online: 12 April 2016}

\section{References}

1. Hanzlick R. Medical examiners, coroners, and public health: a review and update. Arch Pathol Lab Med. 2006;131(3):1274-82.

2. Brend WA. An Inquiry into the statistics of deaths from violence and unnatural causes in the United Kingdom. London: Charles Griffin and Co; 1915.

3. Coroners Act 2008 (Vic). 2008. http://www.austlii.edu.au/au/legis/vic/consol_ act/ca2008120/. Accessed 1 April 2014.

4. Courts and Tribunals Judiciary. Reports to prevent future deaths. 2016 https://www.judiciary.gov.uk/relatedoffices-and-bodies/office-chief-coroner/ pfd-reports/. Accessed 7 April 2016.10.1186/s12961-016-0096-1

5. McGowan CR, Viens AM. Death investigation systems and disease surveillance. Epidemiol Infect. 2010;15:1-5.

6. McGowan CR, Viens AM. Reform of the coroner system: a potential public health failure. J Public Health. 2010;32(3):427-30.

7. Hanzlick R, Parrish RG. The role of medical examiners and coroners in public health surveillance and epidemiological research. Annu Rev Public Health. 1996:17:383-409.

8. Centre for Disease Control. Death investigation - United States 1987. JAMA. 1989;261(5):683.

9. Bugeja L, Ibrahim JE, Ozanne-Smith J, Brodie LR, McClure RJ. Application of a public health framework to examine the characteristics of coroners' recommendations for injury prevention. Inj Prev. 2012;18(5):326-33.

10. Conroy C, Russell JC. Medical Examiner/Coroner records: Uses and limitations in occupational injury epidemiologic research. J Forensic Sci. 1990;35(4):932-7.

11. Brison RJ, Pickett W, Berg RL, Linneman J, Zentner J, Marlenga BF. Fatal agricultural injuries in preschool children: risks, injury patterns and strategies for prevention. CMAJ. 2006:174(12):1723-6.

12. Robertson $\mathrm{MD}$, Drummer $\mathrm{OH}$. Responsibility analysis: A methodology to study the effects of drugs in driving. Accid Anal Prev. 1994;26(2):243-7.

13. Driscoll TR, Mitchell RJ, Mandryk J, Healey S, Hendrie A, Hull B. Work-related fatalities in Australia, 1989 to 1992: an overview. Int J Occup Health Saf - Australia New Zealand. 2001;17(1):45-66.

14. Fowler KA, Gladden RM, Vagi KJ, Barnes J, Frazier L. Increase in suicides associated with home eviction and foreclosure during the US housing crisis: Findings from 16 national violent death reporting system states, 2005-2010. Am J Public Health. 2015:105(2):311-6.

15. Smith SG, Fowler KA, Niolon PH. Intimate partner homicide and corollary victims in 16 states: National Violent Death Reporting System, 2003-2009. Am J Public Health. 2014;104(3):461-6.
16. Hartholt KA, Polinder S, van Beeck F, van der Velde N, van Lieshout EM, Patka $P$, et al. End of the spectacular decrease in fall-related mortality rate: men are catching up. Am J Public Health. 2012;102 Suppl 2:S207-11.

17. Schnitzer PG, Covington TM, Dykstra HK. Sudden unexpected infant deaths: sleep environment and circumstances. Am J Public Health. 2012;102(6):1204-12.

18. Routley V. Motor vehicle exhaust gas suicide: review of countermeasures. Crisis. 2007;28(Suppl):28-35.

19. Towner E, Towner J. Developing the history of unintentional injury: the use of coroners' records in early modern England. Inj Prev. 2000;6:102-5.

20. Bugeja $L$, Franklin RC. Drowning deaths of zero- to five-year-old children in Victorian dams, 1989-2001. Aust J Rural Health. 2005;13:300-8.

21. Blum C, Shields J. Toddler drowning in domestic swimming pools. Inj Prev. 2000;6:288-90.

22. Sanders CM, Saltzstein SL, Schultzel MM, Nguyen DH, Stafford HS, Sadler GR. Understanding the limits of large datasets. J Cancer Educ. 2012;27(4):664-9.

23. Young SS, Karr A. Deming, data and observational studies: a process out of control and needing fixing. Significance. 2011:8(3):116-20.

24. Krieger N, Löwy I, Aronowitz R, Bigby J, Dickersin K, Garner E, et al. Hormone replacement therapy, cancer, controversies, and women's health: historical, epidemiological, biological, clinical, and advocacy perspectives. J Epidemiol Community Health. 2005:59(9):740-8.

25. Owens L, Lightfoot J. The National Coroners Information System: a new death and injury surveillance tool. Australasian Epidemiologist. 2000;7(1):24-30.

26. Driscoll TR, Henley G, Harrison JE. The National Coroners Information System as an information tool for injury surveillance. Australian Institute of Health and Welfare: Canberra; 2003.

27. Bugeja L, Clapperton AJ, Killian JJ, Stephan KL, Ozanne-Smith J. Reliability of ICD-10 external cause of death codes in the National Coroners Information System. HIMJ. 2010;39(3):16-26

28. Irwin $M$, Hayen A, Finch C. Methodological issues in using routinely collected electronic population mortality data: Guidelines for using the National Coroners Information System for fatal injury surveillance in NSW. NSW Injury Risk Management Research Centre: Sydney; 2008.

29. Daking L, Dodds L. ICD-10 mortality coding and the NCIS: a comparative study. HIMJ. 2007;36(2):11-21.

30. Department of Justice. NCIS Annual Report 2013-2014. Melbourne: Department of Justice; 2014.

31. Moher D, Liberati A, Tetzlaff J, Altman DG. The PRISMA Group. Preferred reporting items for systematic reviews and meta-analyses: The PRISMA statement. Ann Intern Med. 2009:151(4):264-9.

32. Guyatt GH, Oxman AD, Vist G, Kunz R, Brozek J, Alonso-Coello P, et al. GRADE guidelines: 4. Rating the quality of evidence - Study limitations (risk of bias). JCE. 2011;64(4):407-15.

33. Voight ML, Hoogenboom BJ. Publishing your work in a journal: understanding the peer review process. IJSPT. 2012;7(5):452-60.

34. Woolfenden S, Dossetor D, Nunn K, Williams K. The presentation of aggressive children and adolescents to emergency departments in Western Sydney. J Paediatr Child Health. 2003;39(9):651-3.

35. Driscoll TR, Harrison JE, Bradley C, Newson RS. The role of design issues in work-related fatal injury in Australia. J Safety Res. 2008;39:209-14.

36. Studdert DM, Cordner SM. Impact of coronial investigations on manner and cause of death determinations in Australia, 2000-2007. MJA. 2010;192(8):444-7.

37. Andrews JY, Forsyth S, Wade J, Kinner SA. Sensitivity of a national coronial database for monitoring unnatural deaths among ex-prisoners in Australia. BMC Res Notes. 2011:4:450.

38. Petrass LA, Blitvich JD, Finch CF. Lack of caregiver supervision: a contributing factor in Australian unintentional child drowning deaths, 2000-2009. MJA. 2011;194(5):228-31.

39. Fragar $L$, Pollock $K$, Morton C. The changing profile of Australian farm injury deaths. J Occup Health Saf Aust NZ. 2008;24(5):425-33.

40. Hanssens L. Indigenous dreaming: how suicide in the context of substance abuse has impacted on and shattered the dreams and reality of Indigenous communities in Northern Territory. Australia Aboriginal Isl Health Work J. 2007:31(6):26-34

41. Walter SJ, Bugeja L, Spittal MJ, Studdert DM. Geographic variation in inquest rates in Australia. Health Place. 2012;18(6):1430-5.

42. Freckelton I. The Myers Oration 2005: untimely death, law and suicidality. Psychiatr Psychol L. 2005;12(2):265-78.

43. Pridmore S, Kuipers P, Appleton J. The 'Operationalized Predicaments of Suicide' (OPS) applied to Northern Territory coroners' reports. Asian J Psychiatr. 2013;6(3):214-7. 
44. Driscoll TR, Harrison JE, Steenkamp M. Alcohol and drowning in Australia. Int J Inj Contr Saf Promot. 2004;11(3):175-81.

45. Andrews JY, Kinner SA. Understanding drug-related mortality in released prisoners: a review of national coronial records. BMC Public Health. 2012 12(1):270.

46. McNeilly B, Ibrahim JE, Bugeja L, Ozanne-Smith J. The prevalence of workrelated deaths associated with alcohol and drugs in Victoria, Australia, 2001-6. Inj Prev. 2010;16(6):423-8.

47. Curran J, McD TD. National Coroners Information System: a valuable source of lessons for emergency medicine. Emerg Med Australas. 2012;24(4):442-50.

48. Cheung YTD, Spittal MJ, Pirkis J, Yip PSF. Spatial analysis of suicide mortality in Australia: investigation of metropolitan-rural-remote differentials of suicide risk across states/territories. Soc Sci Med. 2012;75(8):1460-8.

49. Andrew NE, Gabbe BJ, Wolfe R, Cameron PA. Trends in sport and active recreation injuries resulting in major trauma or death in adults in Victoria, Australia, 2001-2007. Injury. 2012;43(9):1527-33.

50. Franklin RC, Scarr JP, Pearn JH. Reducing drowning deaths: the continued challenge of immersion fatalities in Australia. MJA. 2010;192(3):123-6.

51. Ehsani JP, McNeilly B, Ibrahim JE, Ozanne-Smith J. Work-related fatal injury among young persons in Australia, July 2000-June 2007. Saf Sci. 2013;57:14-8

52. Hanssens L. Imitation and contagion contributing to suicide clustering in indigenous communities: time-space-method cluster analysis. Aboriginal |s| Health Work J. 2008;32(3):28-35.

53. Bambach MR, Grzebieta RH, McIntosh AS. The crash mechanics of fata motorcycle-barrier collisions in Australasia. J Transp Safety Security. 2013; 5(1):66-77.

54. Pilgrim JL, Gerostamoulos D, Drummer OH. Deaths involving MDMA and the concomitant use of pharmaceutical drugs. J Anal Toxicol. 2011;35(4):219-26.

55. Kaye S, Darke S, Duflou J, McKetin R. Methamphetamine-related fatalities in Australia: demographics, circumstances, toxicology and major organ pathology. Addiction. 2008;103(8):1353-60.

56. Walter SJ, Bugeja L, Spittal MJ, Studdert DM. Factors predicting coroners' decisions to hold discretionary inquests. CMAJ. 2012;184(5):521-8.

57. Young DP, Grzebieta RH. Analysis of the National Coroners Information System as a data source for fatal crashes. Australasian Road Safety Research, Policing and Education Conference. Australasian College of Road Safety: Adelaide; 2008.

58. Fréchède $B$, Mclntosh AS, Grzebieta RH, Bambach MR. Characteristics of single vehicle rollover fatalities in three Australian states (2000-2007). Accid Anal Prev. 2011:43(3):804-12

59. Machlin A, Pirkis J, Spittal M. Which suicides are reported in the media - and what makes them "newsworthy"? Crisis. 2012;34(5):305-13.

60. Jama HH, Grzebieta RH, Friswell R, McIntosh AS. Characteristics of fatal motorcycle crashes into roadside safety barriers in Australia and New Zealand. Accid Anal Prev. 2011:43(3):652-60.

61. Roxburgh A, Bruno R, Larance B, Burns L. Prescription of opioid analgesics and related harms in Australia. MJA. 2011:195(5):280-4.

62. Lippmann JM, Pearn JH. Snorkelling-related deaths in Australia, 1994-2006. MJA. 2012;197(4):230-2.

63. Sveticic J, Too LS, De Leo D. Suicides by persons reported as missing prior to death: a retrospective cohort study. BMJ Open. 2012;2(2), e000607.

64. Jones CB, Ibrahim JE, Ozanne-Smith J. Work-related non-crash heavy vehicle driver fatalities in Australia, 2000-9. Inj Prev. 2011;17(4):271-4.

65. Bell JR, Butler B, Lawrance A, Batey R, Salmelainen P. Comparing overdose mortality associated with methadone and buprenorphine treatment. Drug Alcohol Depend. 2009;104(1-2):73-7.

66. Byard RW, Winskog C. Autoerotic death: incidence and age of victims - a population-based study. J Forensic Sci. 2012;57(1):129-31.

67. Guiney R. Farming suicides during the Victorian drought: 2001-2007. Aust J Rural Health. 2012;20(1):11-5.

68. Mikocka-Walus A, Gabbe B, Cameron P. Motorcycle-related major trauma: on-road versus off-road incidence and profile of cases. Emerg Med Australas. 2010;22(5):470-6.

69. Pilgrim JL, Drummer $\mathrm{OH}$. The toxicology and comorbidities of fatal cases involving quetiapine. Forensic Sci Med Pathol. 2013;9(2):170-6.

70. Tooley GA, Karakis M, Stokes M, Ozanne-Smith J. Generalising the Cinderella Effect to unintentional childhood fatalities. Evol Hum Behav. 2006;27(3):224-30.

71. Brodie LR, Bugeja L, Ibrahim JE. Coroners' recommendations following fatal heavy vehicle crash investigations. Aust NZ J Public Health. 2010;34(2):136-41.

72. Elnour AA, Harrison JE. Suicide decline in Australia: where did the cases go? Aust N Z J Public Health. 2009;33(1):67-9.
73. Pridmore S, Fujiyama H. Suicide in the Northern Territory, 2001-2006. Aust NZ J Psychiatry. 2009:43(12):1126-30.

74. Dailey NJ, Norwood T, Moore ZS, Fleischauer AT, Proescholdbell S. Evaluation of the North Carolina Violent Death Reporting System, 2009. NC Med J. 2012;73(4):257-62.

75. Huguet N, Kaplan MS, McFarland BH. The effects of misclassification biases on veteran suicide rate estimates. Am J Public Health. 2014;104(1):151-5.

76. Malay S, Shauver MJ, Chung KC. Applicability of large databases in outcomes research. J Hand Surg. 2012;37(7):1437-46.

77. Park HS, Lloyd S, Decker RH, Wilson LD, Yu JB. Limitations and biases of the surveillance, epidemiology, and end results database. Curr Probl Cancer. 2012;36(4):216-24

78. Kassirer JP, Campion EW. Peer review: crude and understudied, but indispensable. JAMA. 1994;272(2):96-7.

79. Goldbeck-Wood S. Evidence on peer review - scientific quality control or smokescreen? BMJ. 1999;318(7175):44-5.

80. Stahel PF, Moore EE. Peer review for biomedical publications: we can improve the system. BMC Med. 2014;12(1):179.

81. Dwan K, Altman DG, Arnaiz JA, Bloom J, Chan AW, Cronin E, et al. Systematic review of the empirical evidence of study publication bias and outcome reporting bias. PLoS One. 2008;3(8):e3081.

82. Ioannidis JPA. Why most published research findings are false. PLoS Med. 2005;2(8):696-701.

83. Madigan D, Ryan PB, Schuemie M, Stang PE, Overhage JM, Hartzema AG, et al. Evaluating the impact of database heterogeneity on observational study results. Am J Epidemiol. 2013;178(4):645-51.

84. Comstock RD, Mallonee S, Jordan F. A comparison of two surveillance systems for deaths related to violent injury. Inj Prev. 2005;11(1):58-63.

85. Edwards D, Bell J. Cancer registries - future development and uses in Britain. J Public Health Med. 2000;22(2):216-9.

86. Smith PM, Stock SR, McLeod CB, Koehoorn M, Marchand A, Mustard CA. Research opportunities using administrative databases and existing surveys for new knowledge in occupational health and safety in Canada, Quebec, Ontario and British Columbia. Can J Public Health. 2010;101 Suppl 1:S46-52.

87. Weiskopf NG, Weng C. Methods and dimensions of electronic health record data quality assessment: enabling reuse for clinical research. J Am Med Inform Assoc. 2013;20(1):144-51.

88. McGovern C, Cusack DA. The case for a cost-effective central coronial database following an analysis of coronial records relating to deaths in nursing homes. J Forensic Leg Med. 2014;25:21-5.

\section{Submit your next manuscript to BioMed Central and we will help you at every step:}

- We accept pre-submission inquiries

- Our selector tool helps you to find the most relevant journal

- We provide round the clock customer support

- Convenient online submission

- Thorough peer review

- Inclusion in PubMed and all major indexing services

- Maximum visibility for your research

Submit your manuscript at www.biomedcentral.com/submit
) Biomed Central 